\section{No a la violencia contra la mujer}

"Debemos llevar a los culpables ante la justicia y poner fin a la cultura de la impunidad"

Bianca Jagger ${ }^{2}$

Recibido: 20 de febrero de 2013 / Aprobado: 11 de junio de 2013

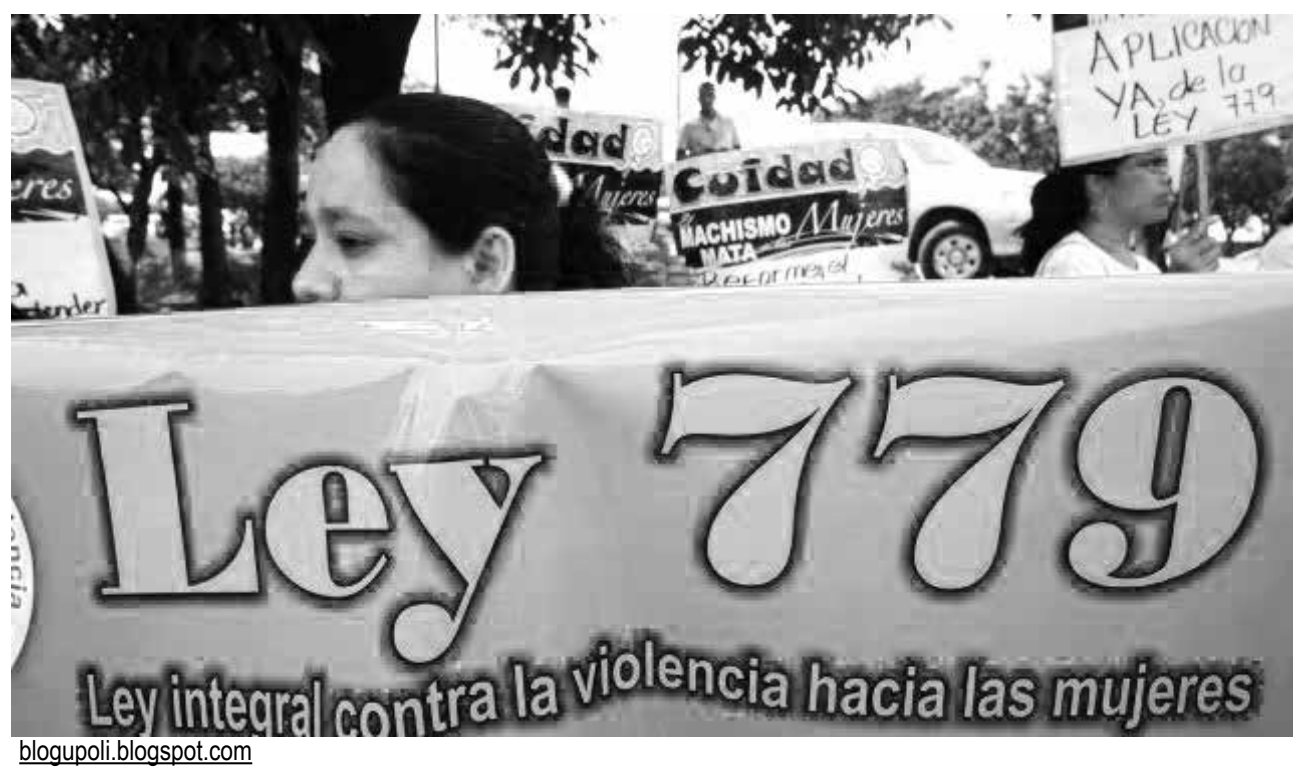

$\mathrm{E}$ s un honor y un placer dirigirme a ustedes durante la celebración del Festival Internacional de la Poesía de Granada, para conmemorar a nuestro tesoro nacional, el poeta Ernesto Cardenal, una personalidad que ha contribuido e inspirado a tantos en los campos de las artes, la literatura, la teología y la política de nuestro país. Es un privilegio estar con ustedes en la bella ciudad de Granada.

Nací en Managua y viví mi infancia y adolescencia bajo el régimen represivo de la nefasta dictadura somocista. Aprendí de primera mano el significado de la opresión, la injusticia social y económica. Salí de Nicaragua con una beca del gobierno francés para estudiar ciencias políticas en París.

Muchas razones, tanto personales como profesionales, me han movido a regresar a Nicaragua en este momento. Mi regreso me llena de tristeza y alegría al mismo

1 Discurso pronunciado en el Festival Internacional de la Poesía de Granada, en Nicaragua el 18 de febrero de 2013.

2 Pensadora y activista mundial por la defensa de los derechos humanos. Bianca Jagger es fundadora y presidenta de la organización The Bianca Jagger Human Rights Foundation, Embajadora de Buena Voluntad del Consejo Europeo, y Miembro del Consejo de Liderazgo del Directorio Ejecutivo de Amnistía EE.UU,

\section{RESUMEN}

Bianca Jagger, pensadora y activista mundial por la defensa de los derechos humanos, esta vez centra su análisis en la violencia contra la mujer en el mundo y en Nicaragua, su país natal, a la cual considera una verdadera pandemia que hay que detener. Ilustra la situación con abundante información en países como: Guatemala, India, Sudáfrica, la ex Yugoslavia, Ruanda, etc.

Palabras clave: violencia, mujer, pandemia, derechos humanos, progreso.

\section{ABSTRACT}

This time, Bianca Jagger, a global thinker and activist for defense of human rights, has focused her analysis on violence against women in Nicaragua, her native country, and the world, which considers it a true pandemic that must be stopped. She illustrates the situation with plentiful information from some countries such as: Guatemala, India, South Africa, the former Yugoslavia, Rwanda, etc.

Key words: violence, women, pandemic, human rights, development. 
tiempo. Me llena de emoción haber sido nombrada como invitada especial en este festival.

Estoy aquí también para enterrar a mi amado hermano Carlos, quien falleció el 24 de enero de este año. Su muerte fue una gran pérdida y me causa profunda tristeza. Pero me imagino que él estará feliz de saber que va a descansar en nuestra querida Nicaragua. Espero que cuando me llegue el momento, descansaré a su lado.

Algunos de ustedes sabrán que desde hace más de treinta años he sido defensora de los derechos humanos y de la protección del medio ambiente. En 2006 inauguré mi organización, la Bianca Jagger Human Rights Foundation, para ser una fuerza de cambio y una voz para los miembros más vulnerables de nuestra sociedad, alcanzar la justicia social, erradicar la pobreza, proteger los derechos de los indígenas, hacer frente a la amenaza del cambio climático, y hablar por las futuras generaciones.

A lo largo de los años, en el transcurso de mis campañas, mi trabajo me ha llevado a muchos lugares del mundo en América, África, Asia y Europa. Y ahora me trae de vuelta a Nicaragua, mi tierra.

ONU Mujer nos ha invitado a mí y a mi organización BJHRF a colaborar con sus proyectos en Nicaragua para promover la igualdad de género, la prevención y eliminación de la violencia contra la mujer, el desarrollo económico y la participación política de la mujer.

\section{En todo el muindo hay una cultura de tolerancia hacia la violencia contra las mujeres}

Esta es una causa muy importante para mí. Después del divorcio de mis padres cuando tenía diez años de edad, mi madre se vio divorciada, sin profesión y con tres niños pequeños que mantener. Vi cómo fue discriminada por ser mujer y por su estatus de divorciada. Durante esos años, muy difíciles, ella demostró su fuerza y su valentía. Nunca se rindió.

Mi madre fue una pionera. Creyó en la emancipación de la mujer en los años sesenta, cuando las mujeres en Nicaragua se dedicaban a las labores del hogar y eran vistas como ciudadanas de segunda categoría. Mi madre fue mi heroína.

Sí, es cierto que las condiciones para las mujeres en Nicaragua, en Latinoamericana y en el mundo han mejorado desde entonces y sí, ha habido progreso. Las mujeres han sobresalido en muchos campos. Sí, es cierto que nuestra condición es diferente de la condición de nuestras abuelas y nuestras madres.

Sin embargo, la igualdad de género no se ha logrado, siguen existiendo niveles inadmisibles de discriminación y de violencia contra las mujeres. La cruda verdad es que las mujeres siguen siendo un grupo de la sociedad muy vulnerable.

La violencia contra la mujer es un crimen, y sin embargo es universal. Esto sucede en todos los países del mundo, $\mathrm{y}$ en todos los niveles de la sociedad.

De acuerdo con ONU Mujer, 6 de cada 10 mujeres son víctimas de violencia física y/o sexual en sus vidas.

En Guatemala, 2 mujeres son asesinadas cada día, de promedio.

Cientos de mujeres han sido masacradas en la mortal Ciudad Juárez, México, en las últimas décadas. De acuerdo con The New York Times, en 2012, 60 mujeres fueron asesinadas y abandonadas en una fosa común en las afueras de la ciudad. Estas fosas comunes fueron descubiertas a mediados de los años noventa, y más

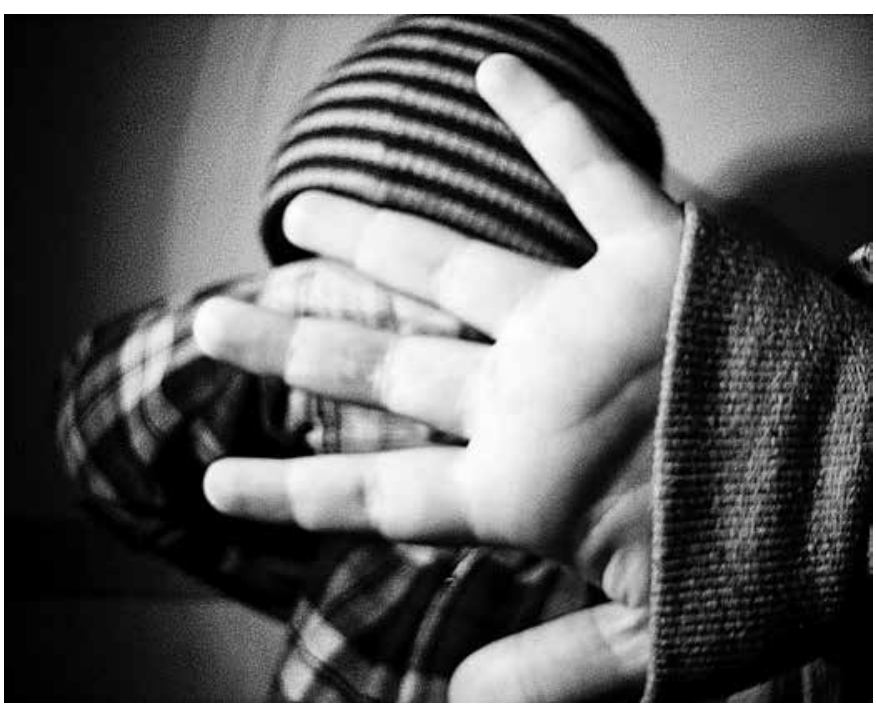

Foto: Miriam Quesada 
cuerpos siguen siendo abandonados cada año. Nadie sabe cómo murieron estas mujeres, ni cómo detener esta masacre.

En India, en 2010, se denunciaron 8.391 casos de muerte en el país. Esto quiere decir una novia cada noventa minutos, de acuerdo con las estadísticas del National Crime Records Bureau of India.

En Sudáfrica, 1 mujer es asesinada cada 6 horas por su pareja.

Vivimos en un mundo donde la violación se ha utilizado como arma de guerra.

En 1993, fui a la antigua Yugoslavia a documentar la violación en masa de mujeres bosnias por las fuerzas serbias

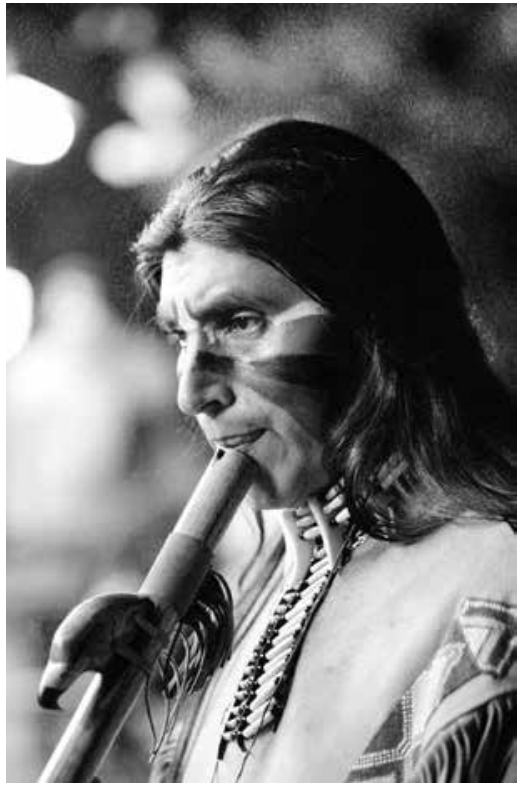

http://www.foto-gratis.es como parte de su campaña de limpieza étnica. Nada me había preparado para el sufrimiento del que fui testigo, o las horribles historias que escuché.

Se estima que durante la guerra de Bosnia hasta 50.000 mujeres fueron violadas sistemáticamente.

Durante el genocidio de Ruanda en 1994 se estima que entre 250.000 y 500.000 mujeres fueron violadas.

A nivel mundial, 60 millones de niñas son sexualmente asaltadas en su camino a la escuela cada año.

De 100 a 140 millones de niñas en todo el mundo, principalmente en África, han sido sometidas a la mutilación genital.

El tráfico ilícito atrapa y destruye las vidas de millones de personas, encerrando a muchas mujeres y niñas en la esclavitud moderna y la prostitución. Las mujeres y las niñas constituyen el $80 \%$ de las 800.000 personas que se estiman víctimas del tráfico a través de fronteras nacionales cada año, y la mayoría, el $79 \%$, son víctimas de la trata con fines de explotación sexual.

Estas cifras terribles hablan por sí mismas. Indican una cultura de tolerancia hacia la violencia contra las mujeres en todo el mundo.
Y me temo que estas terribles estadísticas puedan ser sólo la punta del iceberg. Muchas mujeres tienen miedo de denunciar los casos de violación y de violencia doméstica. Mucha violencia contra las mujeres no se denuncia.

En un estudio de mujeres en quince países, hecho por la Organización Mundial de la Salud, entre el 15 y el $71 \%$ de las mujeres habían sido física o sexualmente abusadas por su cónyuge. Y una quinta parte de las mujeres encuestadas nunca habían denunciado este abuso.

Las mujeres de los pueblos indígenas están particularmente en riesgo. En mayo de 2012, Rashida Manjoo, la relatora especial de la ONU, presentó un informe Sobre la violencia contra la mujer, sus causas y consecuencias a la Asamblea General. Leerlo es impactante. Por ejemplo: "En Guatemala, la experiencia actual de los asesinatos masivos y violentos de las mujeres indígenas viene desde la época colonial, y se incrementó durante 36 años de conflicto armado".

Las mujeres indígenas mayas constituyeron el $88 \%$ de las víctimas de ataques sexuales sistemáticos, un tipo de ataques perpetrados de forma pública y deliberada, sobre todo por militares y paramilitares.

El informe concluye que, en todo el mundo, "los principales fallos de las autoridades son el fracaso de la policía en proteger a las mujeres aborígenes y las niñas de la violencia y en investigar rápida y exhaustivamente cuando ellas desaparecen o son asesinadas".

La lista sigue y sigue. Es una vergüenza, una pandemia global. La violencia contra las mujeres parece estar arraigada en nuestras sociedades. No debería ser. Tenemos que detenerlo. Debemos poner fin a la cultura de la impunidad en todo el mundo.

La violencia es un ciclo que se perpetúa. No solo sufrirá nuestra generación, sino las de nuestras hijas y nuestras nietas, si no exigimos que se ponga fin a esta epidemia. Debemos enseñar a nuestros hijos a querer y respetar a las mujeres. 


\section{La violencia contra la mujer en Nicaragua}

Aquí en Nicaragua hay mucho por hacer. En 2011 hubo 37.000 casos registrados de violencia doméstica o sexual. En un año, cerca de 80 mujeres al año fueron asesinadas por sus esposos. En un país con 6 millones de habitantes, es un número impresionante. La Organización Mundial de la Salud lo considera un indicador de que existe una epidemia de violencia.

El primer estudio sobre la prevalencia de la violencia conyugal contra las mujeres en Nicaragua, titulado Confites en el Infierno, se hizo en 1995. (Ellsberg et. Al., 1996). Según ese estudio, 1 de cada 2 mujeres en Nicaragua ha sido maltratada físicamente en algún momento por su esposo o compañero, y 1 de cada 4 mujeres ha sufrido violencia física en los últimos 12 meses.

La violación y el abuso sexual son todavía comunes en Nicaragua. Amnistía Internacional informa que entre 1998 y 2008, la policía registró 14.377 casos de violaciones en este país. Más de dos tercios de ellos (9.695 casos) eran niñas menores de 17 años.

Una vez más tenemos que afrontar el hecho de que estos números no cuentan toda la verdad: son innumerables los casos de violaciones que no se denuncian. Con demasiada frecuencia, las mujeres que son víctimas de la violencia se ven intimidadas o ignoradas por el sistema legal patriarcal.

En un caso, se informó a Amnistía Internacional en 2010: una mujer fue condenada a 12 años de prisión por ser "cómplice en el delito de violencia sexual." La madre fue a denunciar a la policía que su hija había sido violada repetidamente por su pareja, el padrastro de la niña. La policía arrestó a la madre por no denunciar la violación antes y fue sentenciada a 12 años. Entre tanto no se hicieron esfuerzos para detener al autor y este quedó en libertad mientras la madre estaba en la cárcel.

Hay muchos ejemplos de este tipo en los que, sin ningún escrúpulo, las mujeres son agredidas y asesinadas con impunidad en Nicaragua.

Sandra Ramos, fundadora y directora del Movimiento de Mujeres Trabajadoras y Desempleadas "María Elena
Cuadra", dice: Nicaragua es "muy machista y patriarcal ... la revolución no reconoció sus derechos como mujeres, como feministas". "Los sandinistas aliviaron la pobreza, pero fueron muy lentos para defender los derechos de las mujeres."

En Nicaragua, la "Ley sobre la Violencia contra la Mujer", que entró en vigor el 22 de junio de 2012, es un paso en la buena dirección. Pero tenemos que hacer más, mucho más.

\section{Esperanza}

No todas las noticias son malas. He visto algunas iniciativas durante mi visita a Centroamérica que me ofrecen esperanzas.

En El Salvador, recientemente, participé en la Consulta Regional para la Prevención y Eliminación de la Violencia contra la Mujer. La conferencia fue organizada por ONU Mujeres y por el ISDEMU, una organización dirigida por la Primera Dama de El Salvador, la doctora Vanda Pignato.

Mientras estaba en El Salvador visité un proyecto, la Ciudad de la Mujer, en Santa Ana. Ciudad de la mujer es un proyecto inspirador, con la capacidad dar autonomía a la mujer e introducir cambios en sus vidas. Brinda los servicios de medicina, ayuda legal y apoyo económico en un ambiente seguro.

ONU Mujeres quisiera que en Nicaragua se llevara a cabo un proyecto similar. Estoy convencida que la Ciudad de la Mujer es un modelo pionero que necesita ser emulado no solo en Nicaragua y Latinoamérica, sino en el mundo entero.

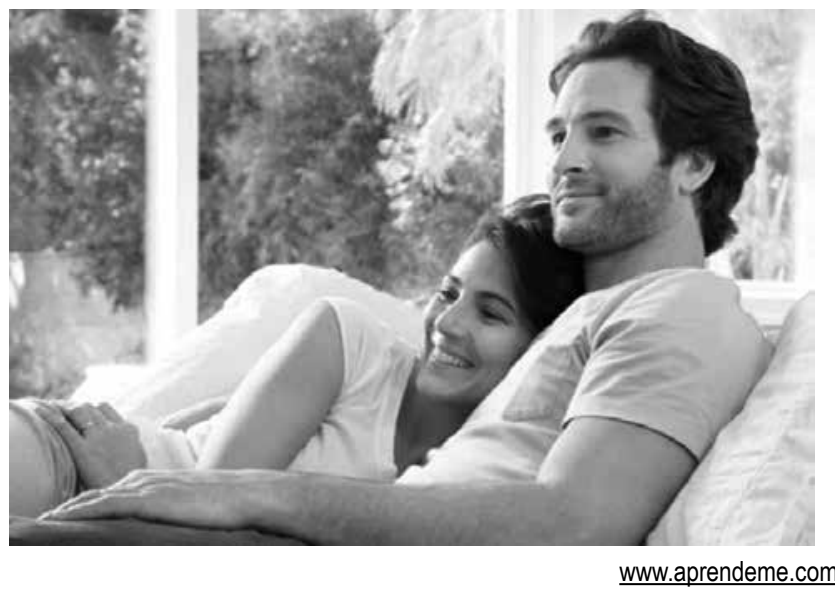


El 14 de febrero de 2013, Eve Ensler, la autora de los Monólogos de la vagina, organizó un movimiento de alcance mundial, One Billion Rising, Un Billon en Pie. Ella hizo un llamamiento a "romper el muro patriarcal de opresión y negación, transformar la mentalidad que ha convertido la violencia en algo normal, poner a las mujeres supervivientes en contacto con sus cuerpos, su fuerza, su determinación, su energía y bailar para mostrar la voluntad del mundo de hacer que la violencia contra las mujeres sea por fin inaceptable". One Billion Rising convocaba a las mujeres de todo el mundo y a los hombres que las quieren a salir de sus escuelas, oficinas, casas, y bailar en la calle.

Desde flash mobs en Florida hasta multitudes bailando al son de la música dangdut en Yakarta, pasando por un zumbatrón aquí, en Nicaragua, al que yo asistí, millones de hombres y mujeres en 203 países se pusieron en pie y bailaron en una demostración mundial de unidad.

Fue una declaración de las mujeres de todo el mundo de que se niegan a seguir soportando la violencia, los abusos y las violaciones. De que esto debe acabar.

\section{Escritores y Artistas}

Los intelectuales, escritores, poetas y artistas han asumido importantes roles través de la historia en defensa de los principios democráticos en pro de los derechos humanos, las libertades civiles y la libre expresión. Han registrado y denunciado los abusos y horrores de cada época. Hoy hago un llamado a los intelectuales, poetas, escritores y artistas a que se unan a la campaña de ‘No a la Violencia Contra la Mujer'.

Las mujeres debemos emprender una revolución no violenta

\section{La Fundación Bianca Jagger en Pro de los Derechos}

Humanos trabaja mano a mano con los artistas. Nuestro primer evento para recaudar fondos, "Las Artes en pro de los Derechos Humanos", estuvo dedicado al gran artista chino Ai Weiwei, quien aún continúa bajo arresto domiciliario en Pekín, ilegalmente detenido por sus creencias políticas.

Los escritores, los poetas y los artistas pueden hacernos entender el sufrimiento humano de una forma que ninguna estadística podría. Basta con leer la cruda descripción del suplicio femenino en el poema Las Mujeres Campesinas de El Cuá, de Ernesto Cardenal, para darse cuenta que tal afirmación es verdadera. Empieza así: "Voy a hablarles ahora de los gritos de El Cuá / Gritos de mujeres como de parto..." Les invito a que lean el poema, si aún no lo conocen.

\section{Llamada a la acción: Una revolución no violenta}

Hago un llamado a los líderes mundiales para que hagan lo necesario a fin de acabar con la violencia contra las mujeres y conseguir la equidad de género. Debemos exigir, por tanto, que todos los países se adhieran a la “Convención para la Eliminación de Todas las Formas de Discriminación contra las Mujeres" y consigan los Objetivos de Desarrollo del Milenio de erradicar la pobreza extrema, conseguir una educación primaria universal, mejorar la salud materna, reducir la mortalidad infantil y combatir el sida.

Debemos negarnos a aceptar que continúen los abusos y la violencia contra las mujeres y las niñas. No podemos permitirnos ser pasivos, teniendo en cuenta a todas las mujeres que sufren violencia, persecución y toda clase de injusticias. Por el bien de nuestras hijas y nietas, no podemos quedarnos sentados y no hacer nada. Al hacerlo, ponemos en riesgo su futuro. La equidad de género no es solamente posible, sino también necesaria. La discriminación y violencia contra las mujeres nos impiden convertirnos en una sociedad libre y equitativa. La violencia contra las mujeres y las niñas representa un crimen contra todos y cada uno de nosotros.

Pongamos fin a la violencia contra las mujeres. Debemos llevar a los culpables ante la justicia y terminar con la cultura de la impunidad.

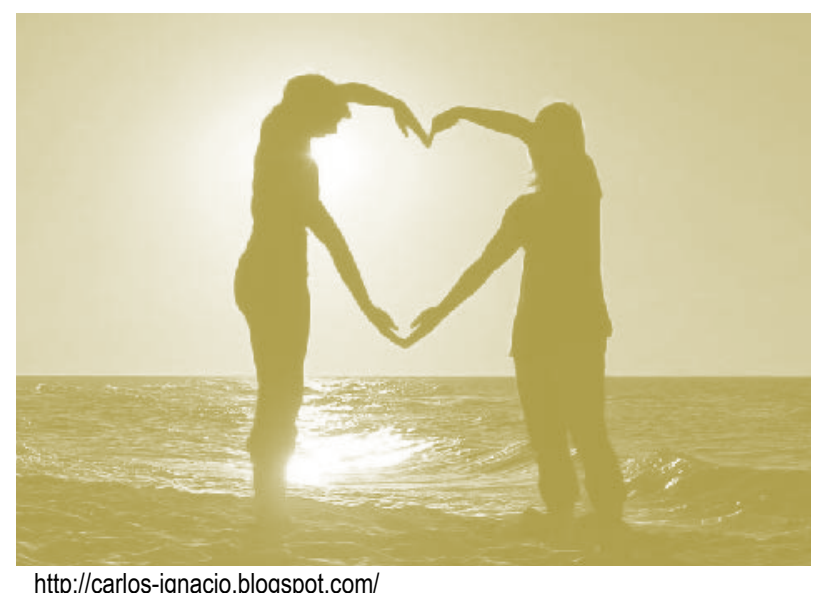

